\title{
Voga esportiva e artimanhas do corpo
}

\author{
Carmen Lúcia Soares* \\ Leonardo Brandão ${ }^{* *}$
}

\begin{abstract}
Resumo: Ao longo da história, inumeráveis formas de intervenção sobre os corpos foram sendo colocadas em prática em diferentes dimensões da vida. Elas expressam maneiras de educar os corpos que se constituíram em processos de inclusão ou exclusão de indivíduos e grupos. Dentre essas dimensões, certamente o esporte possui grande relevância. Assim, neste artigo, temos como objetivo analisálo como modelo universal de organização das práticas corporais contemporâneas e forma especifica de educação do corpo. Para tanto, tomaremos como eixo de nossa discussão uma das práticas contemporâneas de maior visibilidade entre os jovens brasileiros: o skate, ou, como preferem alguns, o skatismo.
\end{abstract}

Palavras-chave: Educação. Corpo. Esportes. Skate.

\section{INTRODUÇÃo}

Entre continuidades e rupturas ao longo da história, inumeráveis formas de intervenção sobre os corpos foram sendo elaboradas e colocadas em prática em diferentes dimensões da vida atestando tanto as renovações e ampliações nos modos de intervir sobre os corpos, quanto a própria ambição de governá-los. Assim podemos dizer que se esboça uma educação do corpo cujos sentidos variam de acordo com os períodos históricos, com suas retóricas próprias, suas asperezas e densidades. (FOUCAULT, 1971).

\footnotetext{
** Programa de Pós Graduação em Educação. Universidade Estadual de Campinas (UNICAMP). Campinas, SP, Brasil. E-mail: soares.carmenlucia@gmail.com

** Programa de Pós-graduação em História Social.Pontifícia Universidade Católica de São Paulo. São Paulo, SP, Brasil. E-mail: brandaoleonardo@uol.com.br
} 
No fio do tempo, esta educação especializa-se e ensaia uma compreensão total do corpo: da intimidade de sua fisiologia, de sua anatomia, recenseando e comparando as forças físicas e seu desenvolvimento, construindo raciocínios e argumentos que permitam uma análise mais profunda de suas funções orgânicas, da ordem dos gestos e de suas eficácias.

Para este artigo nós definimos a educação como um processo múltiplo, polissêmico, que exige e mobiliza análises particulares, finas e delicadas; esse processo não se resume ao que se passa no âmbito escolar e às aprendizagens e conteúdos próprios desse lugar educativo, mesmo que consideremos o importante papel desempenhado pela escola nas aprendizagens sociais. O que queremos reafirmar aqui é que o sentido dado por nós à educação implica modos diversos e plurais de inserção ou de exclusão de indivíduos em processos sociais mais amplos.

Se as sociedades elaboram estratégias para excluir ou incluir indivíduos em distintos processos culturais, elas elaboram igualmente técnicas, pedagogias e políticas para tornar suas ações consequientes. As diferentes pedagogias do corpo, expressas pela forma como uma sociedade representa a alimentação, as roupas, as doenças, as curas, a sexualidade, os divertimentos entre outras dimensões da vida, foram certamente, ao longo do tempo, maneiras de educar os corpos que se constituíram em processos de inclusão ou exclusão de indivíduos e grupos. Nós podemos assim ver ali, nessas pedagogias, a existência de signos e de marcas desta educação nos corpos aonde o esporte vem sendo, talvez, a mais potente.

Ações físicas regradas e reguladas, utilização de técnicas especializadas que permitem o registro cada vez mais preciso e a comparação cada vez mais apurada de forças físicas, das funções orgânicas, da ordem dos gestos e de suas eficácias, das dimensões dos espaços, enfim, de uma verdadeira taxionomia dos exercícios físicos são dimensões estruturantes do desenvolvimento dessa educação do corpo mais especializada e que vai configurar o chamado esporte moderno. 
Assim, seria pertinente não apenas olhar o resultado destas ações no fio do tempo, e que resultaram no que se denomina de esporte, mas, estudar antes de tudo, aquilo que as determinou. É deste modo que para nós, o esporte emerge como um discurso especializado visando uma educação específica do corpo que ultrapassa e alarga seu território de ação, de intenção e, sobretudo, de intervenção, transformando-se em pedagogia, em técnica, em política.

O processo de transformação de diferentes práticas corporais em esporte é, certamente, uma das mais esmagadoras formas de massificação de gestos e de comportamentos. Este processo impõe a lógica da cultura esportiva como espetáculo, da autonomia da técnica, de um tipo de treinamento do corpo (VIGARELLO, 2006 ; VAZ, 1999) $)^{1}$, e da performance física visando a competição que se estende a outras esferas da vida.

O modelo esportivo invade a vida cotidiana, as escolas, as empresas, os lares e toda uma expectativa de educação do corpo, de saúde e, no limite, da vida, se constitui a partir deste modelo. Não seria demasiado lembrar aqui das metáforas esportivas que se impõe cotidianamente, tornando-se um automatismo de linguagem e de pensamento em numerosos domínios, sempre como injunção normativa em direção à performance, a sobrepujança, ao quantitativo da vida. O esporte ocupa os imaginários humanos, individuais e coletivos e os estádios contaminam as almas (REDEKER, 2008, 45).

Este artigo tem como objetivo analisar o esporte como modelo universal de organização das práticas corporais contemporâneas e forma específica e especializada de educação do corpo.

\footnotetext{
'Sobre o treinamento corporal ao longo da história, ver: VIGARELLO In: COURTINE, 2006, p.163 - 197 e VAZ, 1999.
} 


\section{A ARQUITETURA ESPORTIVA: UM DISCURSO MATERIAL UNIVERSALIZANTE}

Uma dimensão não negligenciável do que denominamos educação do corpo concerne à arquitetura, compreendida aqui como um discurso material (PERELMAN, 2008; ZARANKIN, 2001 ou 20022; SOARES, 2005) ${ }^{2}$. Assim, poderíamos indagar sobre a intensa e extensa universalização de aparatos arquitetônicos desenhados pelo esporte moderno e, desse modo, pensarmos em uma educação do corpo bastante determinada pela sua lógica e conteúdo. $\mathrm{O}$ aparato arquitetônico esportivo que compreende, também, um conjunto de equipamentos destinado às práticas corporais revela de modo agudo, um desejo de padronização de atividades às quais parcelas significativas da população são "educadas" a consumir; essa parece ser a única forma legítima e possível de exercitar o corpo, ao largo de atividades específicas que constituem a vida quotidiana.

A arquitetura e, particularmente em nosso estudo, uma arquitetura esportiva pode ser compreendida como um discurso material que combina vontade, conhecimento e poder constituindose como parte da memória coletiva e individual das sociedades. Desse modo, uma arquitetura esportiva poderia revelar modos de pensar e agir em relação a uma determinada educação do corpo, a um tipo específico de práticas, de saberes e de um estilo de vida a ser consumido de maneira universal. A arquitetura é, assim, uma outra voz que narra histórias vividas e condiciona indivíduos e populações inteiras. Resultado, portanto, de intenções e de invenções, a arquitetura esportiva é condicionada por uma sucessão densa e tensa de atos humanos que tecem os lentos processos de educação dos corpos, de sua liberdade e de sua opressão. Pensar este aparato arquitetônico como discurso material (ZARANKIN, 2002) permite uma compreensão, no âmbito das práticas corporais, daquilo que Foucault denominou controle das populações (FOUCAULT, 1999).

${ }^{2}$ Ver entre outros: Marc Perelman, 2008; Andrés Zarankin, 2002; Carmen Lúcia Soares, 2005.

Movimento, Porto Alegre, v. 18, n. 03, p. 11-26, jul/set de 2012. 
Não é nossa intenção neste artigo escrever uma história da arquitetura esportiva, mas tão-somente constatar e registrar o seu poder nas múltiplas esferas de nossas vidas, na intimidade de nossos corpos, nas escolhas de nossos divertimentos. Uma piscina retangular, uma quadra poli esportiva, uma moderna e equipada academia de ginástica, ou, ainda, uma pista construída especialmente para o skate não são apenas inocentes lugares destinados a manter a boa forma, garantir a boa saúde dos indivíduos em uma determinada sociedade, ou, criar espaços de divertimento. Estes lugares concentram e expressam conhecimento e poder são, portanto, discursos materiais que educam, constrangem, socializam e induzem ao consumo de objetos, de práticas, de modos de vida.

O esporte e todo seu aparato revelam, assim, não apenas saberes, mas um estilo de vida destinado a um tipo de consumo universal. Conforme analisa Redeker, "[...] o esporte oferece o paradigma mais puro da mundialização [...] O mundo é um estádio antes mesmo de ser um mercado - ou mais: porque ele é um estádio, ele pode ser um mercado. [...]" (REDEKER, 2008, p.46). Não seria assim no caso do skate, da BMX, dos patins in-line? Não poderíamos citar o caso dos X-Games, ou as "Olimpíadas dos Esportes Radicais", que há anos vem se utilizando de tais práticas para vender personalizadas roupas, mochilas, cadernos e uma infinidade de objetos e de comportamentos?

Em outras palavras, vivemos hoje sob a égide e a voga do esporte (HERENBERGER, 1991) e os espaços destinados e codificados para sua prática, assim como os produtos oriundos de sua massificação, podem ser vistos como uma dimensão pedagógica do poder. Não há, pois nenhuma inocência neste mundo fabricado em referência ao esporte. Bem ao contrario, a voga do esporte que nós vivemos hoje fabrica um modo de viver que transforma a vida cotidiana em uma verdadeira empresa cujos valores invadem suas interfaces, as mais delicadas, seus espaços, os mais íntimos. A arquitetura esportiva é expressão deste modo de vida e, sobretudo, expressão material de uma extensão de práticas e de acesso às práticas corporais sob a forma universalizante fornecida pelo esporte. 
Esta extensão é pois :

[...] um aspecto de uma modificação que afeta o estatuto e a significação do esporte em suas referências com a sociedade. Em uma década o esporte ancorou-se de tal modo na vida quotidiana que ele não mais constitui somente uma forma de lazer, ou, uma atividade corporal específica pensada e organizada na direção de uma performance a ser alcançada, mas, sim, na manifestação de uma referencia generalizada à existência humana: empregado a titulo de referente, de metáfora ou de principio de ação em registros cada vez mais ampliados de nossa realidade contemporânea [...] [o esporte] é um sistema de condutas de si que implica o individuo na transformação de sua autonomia e de sua responsabilidade [...] o esporte é uma técnica de fabricação de autonomia na vida publica[...](HERENBERGER, 1991, p.178 - 179).

\section{TUDO SE TORNA ESPORTE, OU, O APAGAMENTO PROGRESSIVO DA DIVERSIDADE DE PRÁTICAS CORPORAIS}

O fato de que o ano de 2004 foi considerado pelo Conselho da União Européia e do Parlamento Europeu o "Ano europeu de educação pelo esporte" (AEES) (QUEVALL, 2004) ${ }^{3}$, projeto seguido em 2005 pela UNESCO com o "Ano Internacional do Esporte" fornecem uma idéia de como o espírito esportivo e seu mundo de heróis podem invadir as múltiplas esferas da vida pública e privada.

Este detalhe da política internacional, esta escolha do esporte como tema de educação não é anódino e nem ingênuo, ele é, ao contrário, portador de um modelo de comportamento a seguir, de divertimento a consumir. Mas a ambigüidade do esporte, sua face sombria que se exprime pela violência supostamente controlada, as lesões dos atletas cuja gravidade é raramente divulgada, a corrupção dos quadros das instituições esportivas, o doping bastante

\footnotetext{
${ }^{3}$ Grandes eventos esportivos estão programados no Brasil para 2014 como a Copa do Mundo de Futebol e, em 2016, os Jogos Olímpicos.
} 
generalizado, a homofobia declarada, o culto à performance, entre outros exemplos, revelam de um modo claro as ligações profundas que as sociedades mantém com o esse mundo da sobrepujança e da ultrapassagem continua e infinita dos limites de si mesmo. Sem dúvida o mito fundador do esporte é aquele do afrontamento regrado, do engrandecimento de si, de uma suposta "igualdade" (VIGARELLO, 2002). Mas é :

\begin{abstract}
impossível [...] ignorar em seu processo a existência de incontroláveis desvios, os mais vastos malentendidos, o distanciamento dos projetos iniciais, os equívocos suscitados, entre outros, pela exibição de imagens, os desafios de todos os tipos, os crescentes investimentos. A vontade constante de sobrepujar joga, alias, com os limites; o "sempre mais" convida às inevitáveis transgressões. Situação tanto mais obscura que a vontade de preservar o mito, é aquela de afirmar, custe o que custar, a pureza, de engrandecer a prática, ações que tendem precisamente a dissimular possíveis perversidades (VIGARELLO, 2004, p. 15-16).
\end{abstract}

A emergência de uma cultura da performance oriunda do modelo esportivo invade a vida cotidiana, condiciona os gostos e estimula a competição íntima, condenando toda gestualidade gratuita. Esta cultura tenta desenhar e impor um prazer único: o prazer de ser esportivo. Assim, o espírito esportivo invade a vida civil e a lógica do esporte é universalizada: gestos, regras, consumo de produtos, de lugares e, mesmo de uma arquitetura, como nós mostramos aqui brevemente.

Poderíamos indagar se as imagens do estilo de vida esportivo veiculadas como modelo não educam os corpos de uma maneira muito mais profunda e ampla que outras atividades praticadas de forma gratuita, ao acaso, por puro encantamento e divertimento? Como pensar os corpos e as práticas corporais diversas e singulares, plurais e polissêmicas em meio a esta avalanche de imagens de esporte, com sua lógica interna e seus valores que estimulam de modo constante e continuo o individualismo extremo e a constante ultrapassagem de si? Como apresentar e até mesmo pensar outras 
práticas corporais que não estejam ancoradas no modelo do esporte e, sobretudo, que não sejam nomeadas de "esporte"? É possível resistir ao apelo do esporte como modelo universal de organização das práticas corporais? Como resistir às tentativas do esporte de redesenhar todas as práticas corporais em função de suas próprias referências, de sua lógica interna? As práticas corporais que se constituem fora do que se chama esporte poderão resistir e existir com suas lógicas específicas e singulares, seus conteúdos e mesmo, sua denominação própria?

No próximo tópico trataremos essas questões aqui colocadas, tomando como exemplo uma das práticas corporais de maior visibilidade midiática nos últimos anos e também uma das que mais vem conquistando praticantes entre a juventude brasileira: o skate (ou, como preferem alguns, o skatismo).

\section{RESISTÊNCIAS AO ESPORTE: O CASO DO SKATISMO}

[...] É necessário medir também o lento crescimento das práticas e das competições estabelecidas, das práticas deslizantes em toda sua amplitude, tal como o skate, as pranchas, os patins, jogos corporais com os elementos próprios a estas práticas, com suas engrenagens, flerte com o risco e os extremos [...] o indivíduo contemporâneo sonhase mais livre, mais abandonado à vertigem, aos limites, às sensações. Nada, ainda, que substitua o esporte, é claro, mas pode-se verificar na mesma proporção à existência de práticas que revelam em que medida os jogos físicos são suscetíveis a mudanças, abrindo-se a outros horizontes. (VIGARELLO, 2002, p. 207).

É neste quadro de idéias que nós desejamos refletir aqui acerca do processo de elaboração de um novo universo de práticas corporais inventado na esteira da revolução cultural dos anos de 1950-1970 e que, na maioria das vezes, desenvolveu-se contra a idéia moderna de esporte (CALOGIROU; TOUCHÉ, 1995). Por isso que indagamos sempre como é possível, assim, que todo um universo de 
práticas diversas e singulares possa ser englobado em uma única categoria denominada de esporte e mesmo receber a denominação de esporte? Nosso objetivo aqui não é fazer um inventário de novas práticas corporais, das atividades de aventura ou risco, mas, simplesmente de iniciar um debate acerca da hegemonia do esporte como modelo de organização de todas as práticas corporais contemporâneas e mesmo as que poderiam ser denominadas de tradicionais como seria o caso da Capoeira. Para este artigo, como já afirmamos, tomaremos como exemplo o caso do skate.

O skate pode ser considerado uma prática contemporânea, juvenil e urbana, que implica num certo espírito de aventura e onde a criatividade e o risco constante constituem dois de seus mais importantes eixos. No seu início, ele guardou muitas similitudes com o surf, atividade mais antiga e também plena de múltiplas e singulares referências. Skate e surf são práticas de deslizamento onde a leveza, o equilíbrio e, mais amplamente o domínio de si são qualidades físicas buscadas e valorizadas.

Não há dúvida de que o skate é uma prática corporal complexa e que apresenta inúmeras facetas, tais como a de simples divertimento, "meio de transporte", desafio em direção a si mesmo e ao espaço, entre outras. Deslizar sobre o asfalto das ruas é também um gesto pleno de significações, quase um ritual que implica na relação ser humano/tecnologia/objeto, é um jogo de equilíbrio que alia possibilidade de se deslocar mais rápido, um desafio e a incorporação de um aparelho: a pequena prancha ${ }^{4}$.

Entretanto, essas práticas de deslizamento (como o skate, surf, windsurf, etc) tornam-se, elas também, um "esporte", ou mais precisamente, "esportes radicais"5. Mas, poderíamos aqui nos perguntar por que chamá-las de "esporte" se elas foram construídas a partir de outras lógicas e, sobretudo, de outra ética, de outros valores? Por que não utilizarmos simplesmente a expressão "práticas

\footnotetext{
${ }^{4}$ No vocabulário dos praticantes de skate, a prancha que utilizam sobre os eixos e rodas é denominada shape.

${ }^{5}$ De acordo com POCIELLO, In SANT'ANNA, 1995, essas práticas também são conhecidas como " esportes californianos ".
} 
corporais"? O skate, por exemplo, faz parte de um universo de práticas que "[...] desde os anos de 1970-1980 desenvolveram-se à margem dos esportes tradicionais. Inúmeras dentre elas reivindicam uma contracultura, um pertencimento especifico, esta resistência em direção às instituições [...]" (VIGARELLO, 2006, p. 189).

As práticas de deslizamento aportam novas sensações corporais, novas experiências, novos sentimentos e são expressão de uma sociedade que vai banir o imobilismo. Por que não pensarmos tais atividades como uma espécie de resistência à lógica do esporte e não o seu alargamento conceitual, uma vez que esse alargamento conceitual implica uma subordinação dessas atividades à lógica esportiva e, gradualmente, um apagamento de suas liberdades em nome do treinamento, da competição e do mercado.

Não há dúvidas que o skate vem sendo "engolido" pelo esporte nos últimos anos. Sua presença nos X-Games ${ }^{6}$ ou no Mallof Money $\mathrm{Cup}^{7}$ (que no ano de 2011 distribuiu a quantia de US\$ 2 milhões de dólares para os skatistas melhores ranqueados) são provas mais do que concretas de quão avançado se encontra esse processo. No entanto, ele também resiste ao "esporte" quando seu uso ocorre nos espaços não institucionalizados, quando é intempestivamente praticado nas ruas, saltando por escadas ou deslizando por corrimãos; transfigurando assim o espaço público e, dessa forma, orientandose por uma lógica muito distinta das tabelas, dos pódios e medalhas.

Em suas mídias especializadas, por exemplo, alguns articulistas (que também são praticantes de skate) já se mostram incomodados com essa contaminação e massificação do esporte sobre o universo do skate e, a longo prazo, temem que isso possa "causar danos irreversíveis" (REVISTA, 2011, p. 22). No relato transcrito abaixo, o skatista Douglas Luís Prieto comenta cinco termos esportivos que vem, cada vez mais, tornado o skate "igual a tudo aquilo que a gente detesta" (REVISTA, 2011, p.22):

${ }^{6}$ Disponível em: http://espn.estadao.com.br/xgames. Aacesso em 25/10/2011.

${ }^{7}$ Disponível em: http://www.mallofskateboarding.com,. Acesso em 25/10/2011

Movimento, Porto Alegre, v. 18, n. 03, p. 11-26, jul/set de 2012. 
1 - ATLETA: Skate não é esporte, e, portanto, skatista não é atleta. Imagine a mídia criticando algum skatista porque ele apareceu na sessão com uma protuberância abdominal excessiva. Ou alguém que se afaste das sessões por algum tempo por estar fazendo regime: "depois que eu perder $30 \mathrm{~kg}$, volto a andar".

2 - BOLSA ATLETA: Uma grande conquista, sem dúvida alguma. Conseguir apoio público, num país de Estado ausente, é sempre um feito. Melhor dinheiro no bolso do skatista do que no do corrupto. Mas ver impresso no cartaz "válido para o bolsa atleta" transforma o campeonato de skate numa espécie de concurso público. Só faltam os espertinhos vendendo as apostilas. Pelo menos você pode falar pra sua mãe: "não realizei seu sonho de me ver trabalhando no Banco do Brasil, mas vou participar de um campeonato que vale bolsa atleta". Bom era quando o velho "venha detonar" era suficiente pra animar os skatistas.

3 - BOARDSPORT: Quando o skate vivia o auge da marginalidade, proibido e perseguido, nunca vi ninguém levantando a bandeira de incorporá-lo numa categoria. Agora a situação é outra, bem mais conveniente. Desculpe: skate na água afunda, a lixa esfarela e o rolamento enferruja. E não fica preso no pé.

4 - CAMPEÃO: Seja lá qual for: estadual, mundial, feminino, do quarteirão. Claro que as confederações existem para homologar competições e proclamar seus vencedores, mas esse tipo de título pode servir como facilitador na apresentação de um skatista para leigos. Dentro do skate, é muito melhor dizer que é o cara que domina o IAPI, que acerta 540 body jar, que tem parte no vídeo Extremely Sorry.

5 - TREINAR: Outro termo de difícil aplicação no skate. Treinar pode ser bater 70 escanteios por dia, correr 40 minutos, socar um saco de areia repetidamente por $1 \mathrm{~h}$. Mas alguém repete a mesma manobra 70 vezes por dia? Aí, acrescenta-se outra expressão que começa a ser ouvida: centro de treinamento. (REVISTA, 2011, p. 22) 
Na contramão dessa hegemonia fabricada, portanto, um grande número de praticantes recusa a assimilação ao esporte e continua a transformar os parques, as calçadas, as ruas e as escadas no coração das cidades em lugares de resistência às normas arquiteturais, signo de uma recusa a essa aparente facilidade em se transformar em esporte. Isto contribui para manter uma certa identidade "marginal" do skate e de tudo aquilo que favorece sua existência fora de um mundo construído em referência ao esporte.

\section{UMA EDUCAÇÃO DO CORPO NA DIREÇÃO INVERSA DO ESPORTE: DIFERENÇA E SINGULARIDADE DAS PRÁTICAS}

Uma verdadeira lacuna teórica abre-se diante de nós quando evocamos estas práticas corporais novas ou aquelas ancoradas na tradição ${ }^{8}$. Elas nos interpelam e nos aportam novas lógicas, novas éticas, mas, também, certo silêncio, um tempo de espera. Seria esta uma das razões de não haver necessidade alguma de se precipitar sobre a idéia em voga de um "alargamento do conceito de esporte" para descrevê-las, nem sobre sua denominação como "esporte". Evocar uma outra possibilidade de definir, de nomear e de conceitualizar as práticas corporais fora do conceito e da lógica do "esporte" é, hoje, um verdadeiro desafio para as ciências humanas.

O skate, possivelmente, seguirá existindo com sua lógica própria, seu mundo deslizante, marginal, fora das normas esportivas universais. Pois, como podemos ler em suas publicações especializadas, o próprio fato do skate ficar de fora das Olimpíadas é um motivo de comemoração 9 . Para longe do Olimpo dos esportes, o objetivo de muitos skatistas, como afirma o praticante Alexandre Vianna, "[...] é encontrar picos [lugares] naturais de rua, resultado da engenharia e tecnologia dos centros urbanos, e neles acertar todas as manobras

\footnotetext{
${ }^{8}$ Como é o caso da Capoeira.

9Para o skatista Prieto: "Algumas coisas me fazem acreditar que 2012 será um ano bem interessante para o Skate. O primeiro motivo a ser comemorado: é ano olímpico [Londres], e mais uma vez o Skate está fora dessa. Como não sabemos até quando dura a resistência, vamos celebrando a manutenção de nossa liberdade e independência cada vez que tivermos motivos para isso". (REVISTA, 2012, p. 22).
} 
possíveis. [...] Temos de agradecer a sede de ser diferente que o skatista carrega. Andar de skate. Simplesmente andar de skate é o desafio" (REVISTA, 2003, p. 14).

Deste modo, falar desse mundo deslizante com outras palavras, distanciar este mundo de uma estrutura esportiva é mergulhar no desconhecido destas práticas, pois deslizar, escorregar suavemente sobre o asfalto é um estado de espírito, um modo de vida e que não precisa, necessariamente, estar vinculado ao esporte.

E isto porque, como nos ensina Foucault, os discursos são materiais e recusar a palavra "esporte" buscando outras palavras para definir estas práticas é, pois, resistir. O mundo bem estabelecido fabricado pela instituição esportiva e seus poderes inumeráveis e infinitos insinua-se no interior de quase todas as práticas corporais. Mas o exemplo das práticas deslizantes como a do skate nos permite falar de uma contracultura corporal e assim conjecturar outras possibilidades narrativas e experiências de subjetivação. 


\title{
Sportive vogue and body's tricks
}

Abstract: Throughout history, countless forms of intervention on the bodies were put into practice in different aspects of life. They express ways of educating the bodies that formed in processes of inclusion or exclusion of individuals and groups. Among these dimensions, the sport certainly has great relevance. So in this article, we aim to analyze it as a universal model of organization of the contemporary body practices and specific forms of education of the body. For this, we will take as a point of our discussion of the contemporary practices of visibility among young brazilians: skateboarding, or, as some prefer, the skatismo.

Keywords: Education. Body. Sports. Skateboard.

\begin{abstract}
Voga deportiva y maniobras del cuerpo
Resumen: A lo largo de la historia, innumerables formas de intervención sobre los cuerpos se pusieron en práctica en diferentes aspectos de la vida. Ellas expresan maneras de educar a los cuerpos que se formaron en los procesos de inclusión o exclusión de individuos y grupos. Entre estas dimensiones, sin duda el deporte tiene una gran relevancia. Es por ello que en este artículo, nuestro objetivo es analizarlo como un modelo universal de organización de las prácticas corporales contemporáneas y formas específicas de la educación del cuerpo. Para ello, tomaremos como punto de nuestra discusión una de las prácticas contemporáneas de más visibilidad entre los jóvenes brasileños: el skate, o, como prefieren algunos, lo skatismo.
\end{abstract}

Palabras Clave: Educación. Cuerpo. Deportes. Skate.

\section{REFERÊNCIAS}

BRANDÃO, Leonardo; HONORATO, Tony. Skate \& Skatistas: questões contemporâneas. Londrina: UEL, 2012.

BRANDÃO, Leonardo. A cidade e a tribo skatista: juventude, cotidiano e práticas corporais na história cultural. Dourados: Editora da UFGD, 2011.

CALOGIROU, Claire; TOUCHÉ, Marc. Sport-passion dans la vie: le skateboard. In: Terrain, São Paulo, n. 25, p. 37 - 48. 1995 
CASTRO JUNIOR, Luis Vitor. Campos de visibilidade da Capoeira Baiana: As festas populares, as escolas de capoeira, o cinema e a arte (1955-1985). BrasíliaDF: Ministério do Esporte, 2010. (1 Premio Brasil de Esporte e Lazer de Inclusão Social).

FOUCAULT, Michel. L'ordre du discours: Leçon inaugurale au Collège de France prononcée le 2 décembre 1970. Paris: Gallimard, 1971.

EHRENBERG, A. Le culte de la performance. Paris: Calmann-Lévy, 1991.

MAREY, Etienne-Jules. Le mouvement. Nimes: Éditions Jacqueline Chambon, 2002. (1ère. ed. 1894)

MARINHO, Inezil Penna. Subsídios para o estudo da metodologia do treinamento da capoeiragem. Rio de Janeiro: Imprensa Nacional, 1945.

PERELMAN, Marc. Le sport barbare: critique d'um fléau mondial. Paris: Éditions Michalon, 2008.

POCIELLO, Christian. Os desafios da leveza: as práticas corporais em mutação. In: SANT'ANNA, Denise Bernuzzi (orga.). Políticas do Corpo: elementos para uma história das práticas corporais. São Paulo: Estação Liberdade, 1995.

QUEVALL, Isabelle. Les valeurs éducatives du sport: mythe et réalité. In: VIGARELLO, Georges. (dir.). L'esprit sportif aujourd'hui: des valeurs en conflit. Paris: Universalis, 2004.

REDEKER, Robert. Le sport est-il inhumain? Paris : Édition Panama, 2008.

Revista CemporcentoSKATE, n. 59, 2003.

Revista CemporcentoSKATE, n. 28, 2011.

Revista CemporcentoSKATE, n. 167, 2012.

SANT'ANNA, Denise. Bernuzzi de. Entre o corpo e a técnica: antigas e novas concepções. Motrivivência, Florianópolis, v. 11, n. 15, p. 13-24, ago. 2000.

SOARES, Carmen Lúcia. Práticas Corporais: invenção de pedagogias? In: SILVA, Ana Márcia; DAMIANI, lara Regina. (Org.). Práticas Corporais: Gênese de um Movimento Investigativo em Educação Física. Florianópolis: Nauemblu Ciência \& Arte, 2005. v. 1, p. 43-63.

THOMAS, Jérôme. Corps violents, corps soumis. Le policement des moeurs à la fin du Moyen-Age. Paris: L'Harmattan, 2003.

VAZ, Alexandre Fernandez. Treinar o corpo, dominar a natureza: Notas para uma análise do esporte com base no treinamento corporal. Cadernos CEDES, Campinas, v.19, n. 48, p. 89-108, ago. 1999.

VIGARELLO, Georges. Le corps redressé: histoire d'un pouvoir pédagogique. Paris: Armand Colin, 2001. 
VIGARELLO, Georges. Du jeu ancién au show sportif: la naissaince d'un mythe. Paris: Seuil, 2002.

VIGARELLO, Georges. (dir.) L'esprit sportif aujourd'hui: des valeurs en conflit. Paris: Universalis, 2004.

VIGARELLO, Georges. S'entraîner. In : COURTINE, Jean-Jacques. Histoire du corps: les mutations du regard. Le XXème siècle. Paris : Seuil, 2006. v. 3, p.163197.

ZARANKIN, Andrés. Paredes que domesticam: arqueologia da arquitetura escolar capitalista; o caso de Buenos Aires. Campinas, SP: Centro de História da Arte e Arqueologia, 2002.

Endereço para correspondência

Carmen Lúcia Soares

Rua- Dr.Sampaio Ferraz, $n^{\circ} 151$, apto 124

13024-903-Campinas/SP

Recebido em: 15.03. 2012

Aprovado em: 22.05.2012 
